\title{
Clinical Profile of Patients with Type 2 Diabetes Mellitus at a Tertiary Care Hospital
}

\author{
Tanveer Ahmed ${ }^{1}$ \\ ${ }^{1}$ Assistant Professor, Department of General Medicine, Navodaya Medical College, Raichur, Karnataka.
}

\section{Abstract}

Background: Diabetes mellitus is described as a group of metabolic disorders of multiple etiology characterized by chronic hyperglycemia associated with disturbances of carbohydrate, fat and protein metabolism due to absolute or relative deficiency of insulin secretion and/or action. Diabetes mellitus is associated with significant long term sequels, particularly damage or dysfunction of various organs especially kidneys, eyes, nerves, heart and blood vessels. Subjects and Methods: A pre-structured and pre-tested proforma was used to collect the data. Informed consent was taken from all cases and control subjects. Base line data including age and sex, detailed medical history including conventional risk factors, clinical examinations and relevant investigations were included as part of the methodology. Results: The mean serum FBS level among cases was $146.94 \pm 54.99 \mathrm{mg} \%$ as compared to $86.71 \pm 9.71 \mathrm{mg} \%$ among controls. There was highly significant difference in serum FBS levels among cases and controls. Conclusion: The mean serum PPBS level among cases was $244.26 \pm 96.47 \mathrm{mg} \%$ as compared to $111.96 \pm 8.85 \mathrm{mg} \%$ among controls. There was highly significant difference in serum PPBS levels among cases and controls.

Keywords: Diabetes mellitus, FBS, PPBS.

Corresponding Author: Dr. Tanveer Ahmed, Assistant Professor, Department of General Medicine, Navodaya Medical College, Raichur, Karnataka.

Received: October 2019

Accepted: October 2019

\section{Introduction}

The worldwide prevalence of DM has risen dramatically over the past two decades, from an estimated 30 million cases in 1985 to 382 million in 2013. Based on current trends, the International Diabetes Federation projects that 592 million individuals will have diabetes by the year 2035. ${ }^{[1]}$

Diabetes mellitus is a complex metabolic disease caused by variable interactions between hereditary and environmental factors. It is the most common endocrine disease.

Diabetes is perhaps as old as mankind. Diabetes was recognized as a disease entity in ancient Indian - Ayurvedall and described as the -Madhumehall or honey like urine in reference from Charaka (400 BC). ${ }^{[2]}$

Diabetes mellitus is described as a group of metabolic disorders of multiple etiology characterized by chronic hyperglycemia associated with disturbances of carbohydrate, fat and protein metabolism due to absolute or relative deficiency of insulin secretion and/or action. Diabetes mellitus is associated with significant long term sequels, particularly damage or dysfunction of various organs especially kidneys, eyes, nerves, heart and blood vessels. That imposes a tremendous burden on the individuals with diabetes and on health care system.

Type 2 diabetes mellitus is the most common, accounting for
$80-90 \%$ of the diabetic population. Insulin resistance along with relative or absolute insulin deficiency are seen in these subjects. ${ }^{[3]}$

Type 2 DM frequently remains undiagnosed over a long period of time. Because of relative insulin deficiency, hyperglycemia develops gradually and in the initial stages is not severe enough to give rise to the classical symptoms of diabetes.

The exact pathogenesis of type $2 \mathrm{DM}$ is uncertain. Insulin resistance and $\beta$-cells dysfunction may exist together in established cases, it is not clear which is the primary one. However hyperglycemia, itself is a known causative factor for insulin resistance and $\beta$ - cells dysfunction. Genetic and environmental factors play an important role in the pathogenesis of type $2 \mathrm{DM} \cdot{ }^{[4]}$

Type $2 \mathrm{DM}$ is commonly seen in individuals above 40 years. About $60 \%$ of patients are obese. These patients have high plasma insulin levels. Some of them show mutations in the insulin receptor gene.

Another gene that is expressed only in adipose tissue and its protein product Leptin, is vital in regulating body weight. Plasma levels of leptin are increased in some cases ofType 2 DM. The maturity onset diabetes of young (MODY) is due to defective glucokinase (GK). The GK gene is on chromosome $7 \mathrm{p}$. This mutation produces relative insulin deficiency by increasing threshold for glucose induced insulin secretion.Hepatic nuclear factors (HNF1 $\alpha$ and HNF4 $\alpha$ ) gene 
defects are two other causes of MODY. All these genetic variants of MODY are inherited as autosomal dominant type. ${ }^{[5]}$

Under activity, over eating with obesity is associated with the development type 2 diabetes. Through increasing resistance to the action of insulin, obesity probably acts as a diabetogenic factor.

Regular exercise in early adulthood can significantly reduce subsequent development of type $2 \mathrm{DM}$. It is proposed that malnutrition in utero and in infancy may damage beta cell development at a crucial period, predisposing to type 2 diabetes later in life.

Certain drugs like beta adrenergic agonists, thiazide diuretics, corticosteroids are known to be diabetogenic in nature.

Insulin is produced by the beta cells of the islets Langerhans in pancreas in response to hyperglycemia. Beta cells have GLUT-2[transporter] through which glucose is absorbed. Inside the cells glucose is phosphorylated by glucokinase so hyperglycemia increases cellular metabolism through glycolysis, citric acid cycle with generation of ATP.

ATP opens calcium channels. Increased intracellular calcium activates adenylcyclase, which produces cyclic AMP. This cyclic AMP along with calcium causes insulin secretion. Insulin secretion is enhanced by GTP, secretin, gastrin, proteins amino acids, fatty acids, ketone bodies and sulfonylurea drugs. Inhibition of secretion occurs following $\alpha$-adrenergic stimulation and vagotomy. ${ }^{[6]}$

\section{Subjects and Methods}

A pre-structured and pre-tested proforma was used to collect the data. Informed consent was taken from all cases and control subjects. Base line data including age and sex, detailed medical history including conventional risk factors, clinical examinations and relevant investigations were included as part of the methodology.

For blood investigations, $5 \mathrm{ml}$ of blood was collected under aseptic precautions from selected subjects on overnight fasting of 12 hours.

Hundred patients of type 2 diabetes mellitus between age group of 30-70 years attending General Medicine OPD, Medical College and Hospital, were included in the study. Also hundred healthy volunteers in the age group 30-70 years, sex matched during the same period were included in the study under the control group.

\section{Inclusion Criteria}

Hundred subjects of type 2 diabetes mellitus between age group of 30-70 years attending general medicine OPD at Medical College and Hospital.

\section{Exclusion Criteria}

- Type 1 diabetes mellitus

- Other states associated with altered serum ferritin levels like-o Hemochromatosis

- Chronic alcoholics

- Chronic inflammatory condition like SLE, rheumatoid arthritis o Hepatitis, pancreatitis

- Patients with repeated blood transfusions o Iron deficiency anemia

- Hypothyroidism
- History of Iron Supplementation, pregnancy.

Results

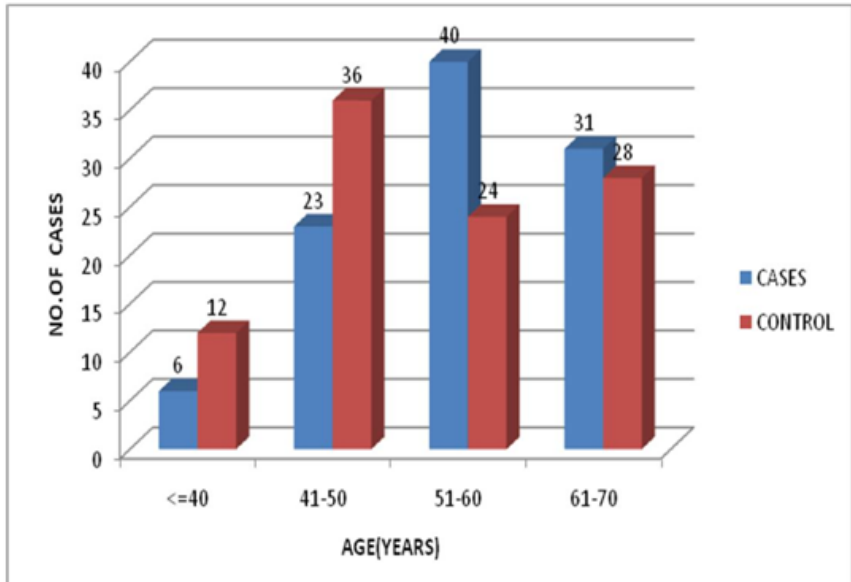

Figure 1: Age Distribution in study group

The mean age was $55.93 \pm 7.89$ years in cases (type 2 diabetes mellitus) in controls (healthy individuals) it was 53.36 \pm 9.56 years. The maximum number of patients were in the age group 41-60 years.

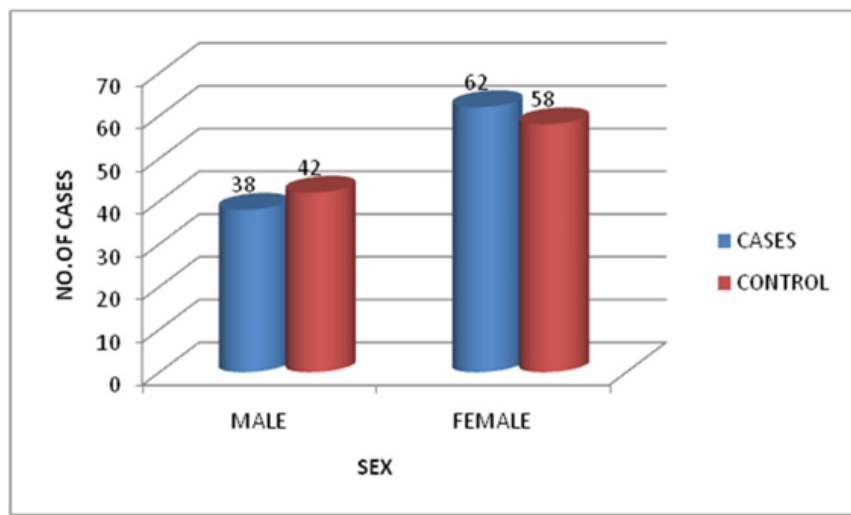

Figure 2: Sex Distribution in study group

Among cases $38 \%$ were males and $62 \%$ were females and among controls $42 \%$ males and 58\% females was the sex distribution in this study.

Table 1(a): Comparison of Glucose parameters in study group

\begin{tabular}{|l|l|l|l|l|l|l|}
\hline \multicolumn{2}{|l}{ FBS } & \multicolumn{2}{l|}{ Cases } & \multicolumn{2}{l|}{ Controls } & \multirow{2}{*}{ Total } \\
\cline { 3 - 7 } \multicolumn{2}{|c|}{} & No & \% & No & \% & \\
\hline \multirow{3}{*}{ FBS } & $<110$ & 25 & 25 & 100 & 100 & 125 \\
\cline { 2 - 7 } & $110-200$ & 57 & 57 & 0 & 0 & 57 \\
\cline { 2 - 7 } & $>200$ & 18 & 18 & 0 & 0 & 18 \\
\hline \multicolumn{2}{|l|}{ Total } & 100 & 100 & 100 & 100 & 200 \\
\hline
\end{tabular}

Table 1(b): Comparison of Glucose parameters in study group

\begin{tabular}{|l|l|l|l|l|l|l|}
\hline \multicolumn{2}{|c|}{ PPBS } & \multicolumn{2}{l|}{ Cases } & \multicolumn{2}{l|}{ Controls } & \multirow{2}{*}{ Total } \\
\cline { 3 - 7 } \multicolumn{2}{|c|}{} & No & \% & No & \% & \\
\hline \multirow{3}{*}{ PPBS } & $<126$ & 5 & 5 & 100 & 100 & 105 \\
\cline { 2 - 7 } & $126-200$ & 38 & 38 & 0 & 0 & 38 \\
\cline { 2 - 7 } & $>200$ & 57 & 57 & 0 & 0 & 57 \\
\hline \multicolumn{2}{|l|}{ Total } & 100 & 100 & 100 & 100 & 200 \\
\hline
\end{tabular}

The mean serum FBS level among cases was $146.94 \pm 54.99$ $\mathrm{mg} \%$ as compared to $86.71 \pm 9.71 \mathrm{mg} \%$ among controls. 
There was highly significant difference in serum FBS levels among cases and controls.

The mean serum PPBS level among cases was $244.26 \pm 96.47$ $\mathrm{mg} \%$ as compared to $111.96 \pm 8.85 \mathrm{mg} \%$ among controls. There was highly significant difference in serum PPBS levels among cases and controls.

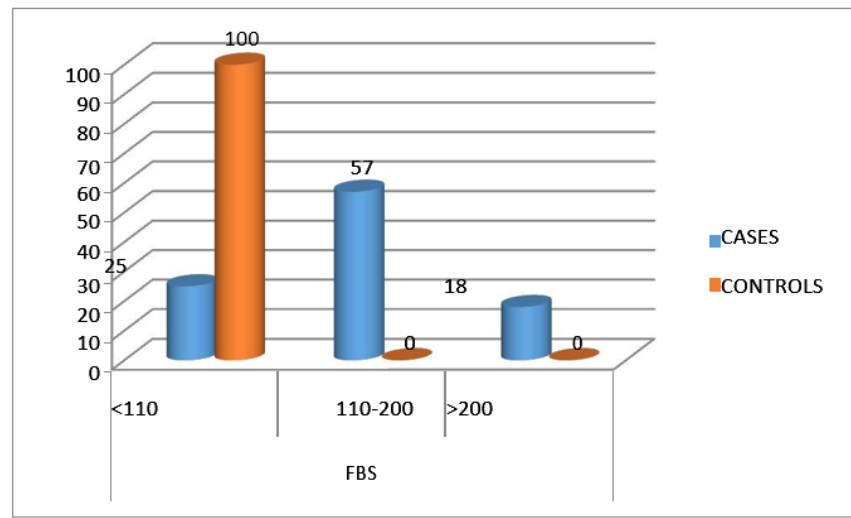

Figure 3: Sex Distribution in study group

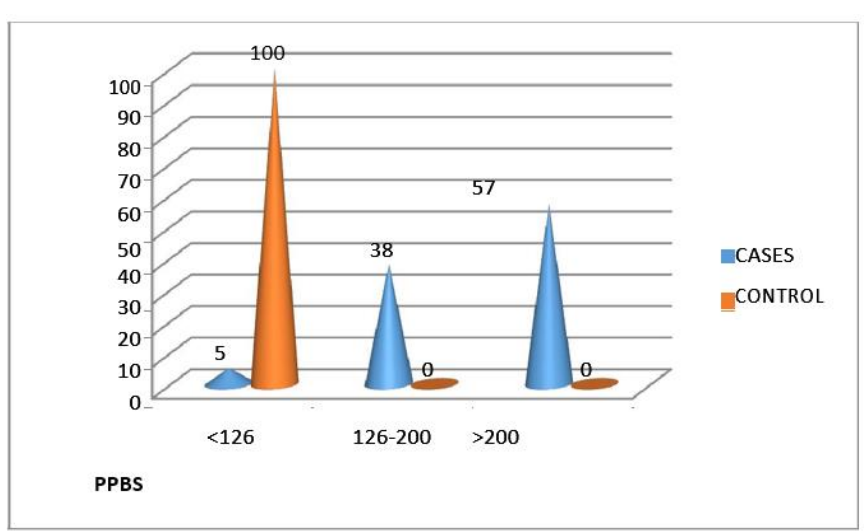

Figure 4: Comparison of Glucose Parameters In Study Group (PPBS) (\%)

\section{Discussion}

Numerous longitudinal and cross sectional studies have provided evidences that hyperglycemia antedates the development of type 2 diabetes mellitus. The insulin resistance can occur in various tissues, liver, muscle, etc. In muscles, the defects in actions are

- Impaired insulin receptor tyro kinase activity,

- Diminished glucose transporters

- Diminished glycogen synthatase and pyruvate dehydrogenase. ${ }^{[7]}$

Thus causes disturbances in major intracellular pathways of glucose disposal, namely glycogen synthesis and glucose oxidation.

In type $2 \mathrm{DM}$, both receptor and post receptor defects contribute to insulin resistance.

In diabetic subjects with moderate to severe hyperglycemia, post binding defects in insulin action are responsible for the insulin resistance.

In subjects with impaired glucose tolerance, the defect may be at insulin binding to its receptor.

\section{First phase}

Plasma glucose remains normal despite demonstrable insulin resistancebecause the insulin levels are increased.

\section{Second phase}

Insulin resistance tends to worsen so that postprandial hyperglycemiadevelop despite elevated insulin concentration.

\section{Third phase}

Insulin resistance does not change but declining insulin secretion causesfasting hyperglycemia.

Glycosuria when plasma glucose concentration exceeds the renal threshold. The severity of the classical osmotic symptoms of polyuria and polydipsia is related to Glucosuria.

Non enzymatic glycosylation results from interaction of glucose derived dicarbonyl precursor like glyoxal, methyl glyoxal etc with the amino group of both intracellular and extra cellular proteins. ${ }^{[8]}$

Once glycation of proteins occur, it is completely irreversible. AGEs cause cross linking between extracellular proteins like collagen and trapping LDL particles.

Circulatory particles modified by addition of AGEs bind to endothelial cells, mesangial cells and macrophages leading to release of growth factors, increased endothelial permeability, increased pro coagulant activity and enhanced fibroblast and smooth muscle cell proliferation, resulting in atherosclerosis andmicroangiopathy.

$\mathrm{HbA}_{1 c}$ reflects average plasma glucose over the previous 8 to 12 weeks. It can be performed at any time of the day and does not require any special preparation such as fasting.

More recently there has been substantial interest in using it as a diagnostic test for diabetes and as a screening test for persons at high risk of diabetes. ${ }^{[9]} \mathrm{HbA}_{1} \mathrm{C}$ is normally about 4 to $6 \%$ of total $\mathrm{HbA}_{1}$ in healthy individuals .Hyperglycemia causes intracellular de novo synthesis of diacyl glycerol from glycolytic intermediates and hence causes activation of PKC. The downstream effect of PKC are alteration of transcription of genes for fibronectin, type 4 collagen, contractile proteins and extracellular matrix protein in endothelial cells, neurons and increased production of VEGF, TGF- $\beta$, PDGF, EGF, IGF-1 leading to diabetic vascular episodes. ${ }^{[10]}$

\section{Conclusion}

- $\quad$ The mean age of diabetes were $55.93 \pm 7.89$ years and controls were $53.36 \pm 9.56$ years. Peak age incidence was seen in the age group of $41-60$ years.

- Among cases $38 \%$ males and $62 \%$ females, among controls $42 \%$ males and $58 \%$ females was the sex distribution in this study.

- The mean FBS was $146.94 \pm 54.99 \mathrm{mg} / \mathrm{dl}$ in diabetes and $86.71 \pm 9.71 \mathrm{mg} / \mathrm{dl}$ in controls $(\mathrm{p}<0.001 * *)$.

- The mean PPBS was $244.26 \pm 96.47 \mathrm{mg} / \mathrm{dl}$ in diabetes and $111.96 \pm 8.85$ in controls $(\mathrm{p}<0.001 * *)$.

\section{References}

1. Suvarna J, Ingle H, Deshmukh CT, - Insullin resistance and beta cell function in chronically trancfused patients of thalassemia majorll Indian pedia 2006; 43: 393-400.

2. FaranakSharifi, N MousaviNasab, H JazebiZadeh, 
2008. IElevated serum ferritin concentrations in prediabetic subjectsll. Diabetes Vascular diseasesRes.5 (1):15-18.

3. Hoskote S S, Joshi S R, - Are Indians destined to be diabetic?\| Journal of associations of physicians of India 2008, 56:225-226.

4. Kolterman DC, Gray RS. Griffin J. Receptor and post receptor defects contribute to the insulin resistance in NIDDM .J. ClinInrests 1981; 68;95.

5. Sumeet Smotra, VR Tandon, Sanjay Sharma, RP Kudyar, -Serum ferritin and type 2 diabetes mellitusll. Jk Science, 2007; 9(4): 164-166.

6. Felber JP, Ferrannini E, Golay A, Meyer HV, - Role of lipid oxidation in pathogenesis of insulin resistance of obesity and type 2 diabetes\| Diabetes, $1987 ; 36: 1341-1350$.

7. Hunt JV, Smith CL, Wolf SP, - Auto oxidative glycosylation and possible involvement of peroxides and free radicals in LDL modification by glucosell. Diabetes, $1990 ; 39: 1420-1424$.

8. Halliwell B, Gutteridge JM, - Role of free radicles and catalytic metal ions in human disease ; an over viewll. Methods enzymol $1990: 186: 1-85$.

9. Sullivan JL, - Iron and the sex difference in heart disease riskll. Lancet 1,$1981 ; 1293-1294$.

10. Salonen JT, Nyyssnen K, Salonen R, - Body iron stores and the risk of coronary heart diseasell. N Engl J Med, 1994 ; 331 : 1159 (letter).

Copyright: (c) the author(s), 2019. It is an open-access article distributed under the terms of the Creative Commons Attribution License (CC BY 4.0), which permits authors to retain ownership of the copyright for their content, and allow anyone to download, reuse, reprint, modify, distribute and/or copy the content as long as the original authors and source are cited.

How to cite this article: Ahmad T. Clinical Profile of Patients with Type 2 Diabetes Mellitus at a Tertiary Care Hospital. Acad. J Med. 2019;2(2):32-35.

DOI: dx.doi.org/10.21276/ajm.2019.2.2.10

Source of Support: Nil, Conflict of Interest: None declared. 